Review

\title{
Ageing, Comorbidity and Frailty-Synergistic Risk Factors for Covid-19 Adverse Outcomes
}

Demelza Emmerton ${ }^{1}$, Samra Khan ${ }^{1}$, Joanne Conway ${ }^{1}$, Daniel Mosby ${ }^{2}$, Ahmed H. Abdelhafiz ${ }^{1, *}$

1. Department of Geriatric Medicine, Rotherham General Hospital, Moorgate Road, Rotherham S60 2UD, UK; E-Mails: d.emmerton@nhs.net; samrakhan123@hotmail.co.uk; joanne.conway3@nhs.net; ahmedhafiz@hotmail.com

2. Sheffield teaching hospitals, Sheffield S10 2JF, UK; E-Mail: dj.mosby34@gmail.com

* Correspondence: Ahmed H. Abdelhafiz; E-Mail: ahmedhafiz@hotmail.com

Academic Editor: Pilar Pérez-Ros

Special Issue: Frailty in Older Adults

OBM Geriatrics

2020, volume 4, issue 3

doi:10.21926/obm.geriatr.2003127
Received: May 31, 2020

Accepted: July 08, 2020

Published: July 10, 2020

\begin{abstract}
With life-expectancy rising globally, the prevalence of ageing, comorbidity and frailty is likely to increase especially in the low and middle income countries. The emergence of the new COVID-19 pandemic has been concentrated in this group of patients and has led to worse outcomes compared to younger and less comorbid populations. This group of patients is at an increased risk of multi-organ consequences of systemic disease. Therefore, systemic assessment of these patients from the outset and optimisation of their pre-existing conditions in addition to the treatment of COVID-19, is required to reduce the risk of multiorgan failure. Decisions regarding escalation of treatment should include frailty assessment along with the overall comorbid condition and function. The expected projection of the ageing population will mean the population is increasingly at risk, locally and globally, of managing a new pandemic, in particular in those low and middle income countries with less access to healthcare resources. Therefore, WHO and governments around the world must consider this potential threat in future health care planning.
\end{abstract}

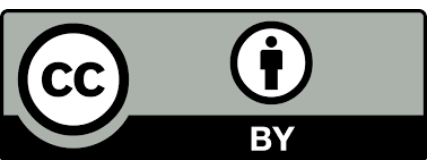

(C) 2020 by the author. This is an open access article distributed under the conditions of the Creative Commons by Attribution License, which permits unrestricted use, distribution, and reproduction in any medium or format, provided the original work is correctly cited. 


\section{Keywords}

COVID-19; frailty; comorbidity; ageing; outcome

\section{Introduction}

The global population is ageing. With this, the risk of infections increases. In December 2019, a pneumonia-like illness was first reported in Wuhan-China caused by a new coronavirus - corona virus disease-2019 (COVID-19) - which has since caused a global pandemic [1]. The incidence, severity and mortality of COVID-19 infection appears to be shifted towards old age, especially in those who are frail and with multiple comorbidities. The most commonly reported comorbid conditions are hypertension, cardiovascular disease, respiratory disease and diabetes mellitus, all of which are more prevalent in older age [2]. Although frailty has not been formally assessed in most COVID-19 published literature, it is possible that frailty was the surrogate marker of old age and the associated comorbidities. Frailty is characterised by dysregulation in the innate and adaptive immunity that leads to increased susceptibility to severe infections. This manuscript reviews the published data on COVID-19 infection and explores the synergistic role of ageing and frailty in increasing the risk of adverse outcomes.

\section{Aging}

Globally, people are living longer. By the year 2050, the number of people aged $\geq 60$ years is expected to reach 2 billion, a surge from a reported 900 million people in 2015 . People $\geq 80$ years are the fastest growing group and will almost quadruple to reach 434 million in 2050 from the current 125 million [3]. The pace of population ageing worldwide is also increasing dramatically. While this demographic shift towards old age, known as population ageing, initially started in highincome countries such as Japan (currently $30 \%$ of the population is already over 60 years old), it is now moving fast towards low- and middle-income countries and in $2050,80 \%$ of all older people are expected to be living in these countries [3].

There is, however, little evidence to suggest that older people today are experiencing their later years in better health than their parents. Although over the last 30 years, the rates of severe disability may have been reduced, there has been no significant change in mild to moderate disability over the same period. In addition to the expected increase in life expectancy, this will be associated with increased prevalence of comorbidity.

\section{Comorbidity}

Patients naturally accumulate comorbidity with increased age and population studies have previously suggested that $31.4 \%$ of those over 85 years will have four or more chronic conditions [4]. Furthermore, there is likely to be a development of subclinical pathology in various organ systems, even in the absence of overt disease, which likely contributes to adverse health outcomes [5]. For example, multi-morbidity has been shown to increase the likelihood of hospital admissions, increase length of stay and the readmission rate. It has also been shown to negatively 
impact on healthcare costs, reduce quality of life and increase the prevalence of dependency, polypharmacy and mortality [6].

With increasing ageing of the population, it is projected that from the years 2015 to 2035, the number of people living with $\geq 4$ comorbidities will almost double (from $9.8 \%$ to $17.0 \%$ ) and more than two thirds of gains in life expectancy after the age of 65 years will be spent living with $\geq 4$ long-term conditions [7]. Comorbidity associated with increased age will lead to the emergence of complex health states that tend to occur later in life and are commonly called geriatric syndromes that include frailty.

\section{Frailty}

Frailty is defined as a state of increased vulnerability to physical or psychological stressors because of decreased physiological reserve in multiple organ systems that cause limited capacity to maintain homeostasis [8]. The prevalence of frailty in older people $>65$ years reaches up to $7 \%$ and up to $40 \%$ in those $>80$ years [9]. In a systematic review of observational population-based studies, the prevalence of frailty was $14 \%-24 \%$. This increased with age and was associated with a poor survival in a dose-response manner [10].

The incidence of frailty is also high. In a systematic review of 46 observational studies involving 120,805 non-frail (robust or pre-frail) community-dwelling participants who were $\geq 60$ years old, from 28 countries, and who survived the median follow up period of 3 years, $13.6 \%$ became frail (incidence rate $43.4,95 \%$ confidence interval $\{\mathrm{Cl}\} 37.3$ to 50.4 , cases per 1000 person-years). The incidence of frailty was significantly higher in pre-frail individuals than robust individuals (incidence rates, $62.7 \%, 95 \% \mathrm{Cl} 49.2$ to 79.8 and $12.0 \%, 95 \% \mathrm{Cl} 8.2$ to 17.5 , cases per 1000 personyears, respectively, $P<0.001)$. Among robust individuals in 21 studies who survived a median follow-up of 2.5 years, $30.9 \%$ became pre-frail, with the pooled incidence rate $150.6(95 \% \mathrm{Cl} 123.3$ to 184.1 ) cases per 1000 person-years. Results of this study suggest that community-dwelling older people are prone to developing frailty [11].

\section{COVID-19}

The respiratory disease COVID-19 is caused by the severe acute respiratory syndrome coronavirus-2 (SARS-CoV-2). The SARS-CoV-2 is a zoonotic virus similar to the previous corona viruses that caused the Severe Acute Respiratory Syndrome (SARS) and the Middle East Respiratory Syndrome (MERS). All the three viral infections commonly present with respiratory symptoms and lead to adverse clinical outcomes especially related to ageing, underlying comorbidities and frailty.

\subsection{Ageing-Related Risk}

In an epidemiological report of 72,314 cases of COVID-19 in China, the majority of cases (89.8\%) were between the age of 30 to 79 years old and the proportion of cases in the elderly (> 60 years) was $44.1 \%$. The overall case mortality rate (CFR) was $2.3 \%$, which increased proportionally with age. The CFR in those aged 70 to 79 years was $8.0 \%$ and in those aged $\geq 80$ years was $14.8 \%$ [12]. $\mathrm{m}$ A study of 48,557 cases and 2,169 deaths, conducted in Wuhan China estimated that the risk of 
mortality from the time of onset of symptoms in those aged $>59$ years was 5.1 ( $95 \% \mathrm{Cl} 4.2$ to 6.1 ) times greater than those aged $30-59$ years [13].

Older age was identified as a risk factor for mortality from COVID-19 pneumonia in a Chinese retrospective, multicentre cohort study (\{odds ratio (OR) 1.10, 95\% confidence interval (CI) 1.03 to1.17, $p=0.004$ ) [14]. Ageing has also been found to predict severity of disease. In a Chinese clinical progression study of COVID-19, age (OR 1.06) was independently associated with ICU admission in multivariate logistical analysis [15].

In another study, old age was a significant risk factor for the development of acute respiratory distress syndrome (ARDS) and the progression from ARDS to death (\{hazard ratio (HR) 3.26, 95\% Cl 2.08 to 5.11; and 6.17, 3.26 to 11.67, respectively) [16]. Ageing appears to play a significant role in mortality rate differences between countries affected. For example, the overall case-fatality rate in Italy (7.2\%) is substantially higher than that in China (2.3\%) but when data are stratified by age groups, the case-fatality rate in Italy and China appear very similar up to the age of 69 years. Individuals aged $\geq 70$ years represent $37.6 \%$ of cases in Italy and only $11.9 \%$ in China from which we may infer that the higher overall case-fatality rate is due to the high prevalence of older age groups in Italy compared to China [17]. Also, in an initial British report of 16,749 patients with severe COVID-19 who were hospitalised, the median age was 72 years (IQR 57, 82). Increasing age was a strong predictor of in-hospital mortality after adjusting for comorbidity (reference age $<50$ years, 50-69yrs HR 4.02 (95\% Cl 2.88 to 5.63, p<0.001), 70-79yrs HR 9.59 (6.89 to 13.34, $p<0.001$ ), $\geq 80 y$ rs HR 13.59 ( $\mathrm{Cl} 9.79$ to $18.85, \mathrm{p}<0.001$ ) [18]. Finally, the recently reported British database analysis of $17,425,445$ NHS registered adults showed that 5,683 deaths were attributed to COVID19 and mortality was strongly and proportionally associated with age. With the data being fully adjusted and the 50-59 age group being used as a reference point, those aged 18-<40 had a risk of only 0.07 ( $95 \% \mathrm{Cl} 0.05$ to 0.1 ), whereas those in the $\geq 80$ years age group had a 12.64 -fold $(95 \% \mathrm{Cl}$ 11.19 to 14.28 ) increased risk of death from COVID-19 [19].

\subsection{Comorbidity-Related Risk}

The Chinese epidemiological report of 72,314 cases of COVID-19 showed that the CFR was high among patients with pre-existing comorbid conditions. CFR was $10.5 \%$ for patients with cardiovascular disease, $7.3 \%$ for diabetes mellitus, $6.3 \%$ for chronic respiratory disease, $6.0 \%$ for hypertension and $5.6 \%$ for cancer [12]. In a meta-analysis of 7 studies including 1,576 patients with COVID-19, the most prevalent comorbidities were hypertension $(21.1 \%, 95 \% \mathrm{Cl} 13.0$ to $27.2 \%)$, diabetes $(9.7 \%, 7.2$ to $12.2 \%)$, cardiovascular disease $(8.4 \%, 3.8$ to $13.8 \%$ ) and respiratory disease $(1.5 \%, 0.9$ to $2.1 \%)$. The pooled odds ratio (OR) for severe illness prediction were 2.36 (95\% $\mathrm{Cl} 1.46$ to 3.83 ) for hypertension, 2.46 (1.76 to 3.44) for respiratory disease and 3.42 (1.88 to 6.22) for cardiovascular disease respectively [2].

In another meta-analysis of 6 studies including 1,527 patients with COVID-19, the incidences of hypertension, cardio-cerebrovascular disease and diabetes mellitus were twofold, threefold and fourfold respectively higher in severe intensive care unit (ICU) patients compared to severe nonICU patients [20]. In a Chinese nationwide analysis of 1,590 hospitalised patients with COVID-19, conducted to evaluate the composite endpoints of admission to intensive care unit, invasive ventilation or death, $8.2 \%$ patients reached to the composite endpoints. A minimum of one comorbidity was present in $25.1 \%$ of patients. Two or more comorbidities were reported in $8.2 \%$ 
of patients. The composite endpoint was documented in $28.5 \%$ of patients who had two or more comorbidities, $19.3 \%$ of patients who had at least one comorbidity as opposed to $4.5 \%$ patients without comorbidities. Significantly, more patients with hypertension $(19.7 \%$ vs. $5.9 \%)$, cardiovascular diseases (22.0\% vs. $7.7 \%)$, cerebrovascular diseases (33.3\% vs. $7.8 \%)$, diabetes ( $23.8 \%$ vs. $6.8 \%)$, COPD ( $50.0 \%$ vs. $7.6 \%)$, chronic kidney diseases ( $28.6 \%$ vs. $8.0 \%$ ) and malignancy $(38.9 \%$ vs. $7.9 \%$ ) reached the composite endpoints compared to those without. Risk factors for reaching the composite end points were COPD \{hazards ratio (HR) $2.681,95 \% \mathrm{Cl} 1.424$ to 5.048 \}, diabetes (1.59, 1.03 to 2.45$)$, hypertension (1.58, 1.07 to 2.32 ) and malignancy $(3.50,1.60$ to 7.64$)$ after adjusting for age and smoking status. The HR was 1.79 (95\% $\mathrm{Cl} 1.16$ to 2.77$)$ among patients with at least one comorbidity and $2.59(95 \% \mathrm{Cl} 1.61$ to 4.17$)$ among patients with two or more comorbidities. This analysis suggests that number of comorbidities proportionally increases the risk of adverse outcomes [21].

In Italy, a chart review of 355 patients who died with COVID-19 showed the mean (SD) number of comorbidities was 2.7 (1.6). Overall, $0.8 \%$ of patients had no comorbidities, $25.1 \%$ had one comorbidity, $25.6 \%$ had 2 comorbidities and $48.5 \%$ had $\geq 3$ comorbidities suggesting that mortality is proportional to number of comorbidities [17]. In the British report of 20,133 patients hospitalised with severe COVID-19, 77\% had a documented comorbidity which was associated with increased hospital mortality [18]. Available data from the countries most prominently affected by COVID-19 is summarised in Table 1 [17, 18, 21, 22].

\subsection{The Frailty Factor}

Frailty is characterised by dysregulation in the innate and adaptive immunity that leads to chronic inflammation and increased susceptibility to severe infections. It may be linked to infectious diseases through common pathways that reduce immunity and increase inflammatory markers. Raised inflammatory markers are a common finding in patients with viral pneumonia [23]. Frailty has also been shown to be associated with poor post-vaccination immune response, increased rates of influenza-like illness and laboratory-confirmed influenza infection [24]. Although frailty was not formally assessed in the published COVID-19 studies, it is possible that it was an important factor that contributed to adverse outcomes. This is not surprising as the official estimates published by the Belgian, French, Irish and Italian governments estimates the proportion of deaths from Covid-19 among care home residents to be $42 \%$ to $54 \%$ [25]. It is also reported that there have been large numbers of deaths in care homes in Italy, Spain, the United Kingdom and the United States but official data for these countries is either incomplete or difficult to interpret [25].

In a US long-term care facility report of 101 residents with COVID-19, the median age was 83 years (range, 51 to 100 ), hospitalization rate was $54.5 \%$ and case fatality rate was $33.7 \%$. Most (94.1\% of 101) facility residents had chronic underlying health conditions, with hypertension (67.3\%), cardiac disease $(60.4 \%)$, renal disease $(40.6 \%)$, diabetes mellitus $(31.7 \%)$, pulmonary disease (31.7\%), obesity (30.7\%) and cancer (14.9\%) being most common [26]. The results suggest that frail care home residents affected by COVID-19 are older than those reported from other community settings and also the number of comorbidities is higher. Interestingly, the majority of patients $(68.3 \%)$ were female in contrast to the higher incidence of COVID-19 in males reported 
elsewhere in community settings. This is likely reflecting the predominance of females in care homes due to their longer life expectancy.

Table 1 International reported data on COVID-19 patients characteristics.

\begin{tabular}{|c|c|c|}
\hline Country & Population & Main findings \\
\hline $\begin{array}{l}\text { China } \\
{[21]}\end{array}$ & $\begin{array}{l}1,590 \\
\text { patients. }\end{array}$ & $\begin{array}{l}\text { A. Mean (SD) age was } 48.9 \text { ( } 16.3 \text { ) years } \\
\text { B. } 25.1 \% \text { have } \geq 1 \text { comorbidity } \\
\text { C. Prevalent comorbidities were hypertension }(16.9 \%) \text { and diabetes } \\
\text { ( } 8.2 \% \text { ) } \\
\text { D. Mortality risk increased by comorbidity (HR } 1.79,95 \% \text { Cl } 1.16 \text { to } \\
2.77 \text { ) for } \geq 1 \text { comorbidity and } 2.59 \text { ( } 1.61 \text { to } 4.17) \text { for } \geq 2 \text { comorbidities. }\end{array}$ \\
\hline Italy [17] & $\begin{array}{l}1625 \text { died } \\
\text { patients }\end{array}$ & $\begin{array}{l}\text { A. Overall case fatality rate } 7.2 \%, 52.3 \% \text { were } \geq 80 \text { years old. } \\
\text { B. Analysis of subsample of } 355 \text { patients: } \\
\text { 1. Mean (SD) age } 79.5 \text { years }(8.1) \text {. } \\
\text { 2. Mean (SD) number of comorbidities } 2.7(1.6) \text {. } \\
\text { 3. } 99.2 \% \text { of patients had } \geq 1 \text { comorbidity. } \\
\text { 4. Comorbidities were diabetes mellitus }(35.5 \%) \text {, ischaemic heart } \\
\text { disease ( } 30 \%) \text {, atrial fibrillation }(24.5 \%) \text {, active cancer }(20.3 \%) \text {, stroke } \\
(9.6 \%) \text { and dementia ( } 6.8 \%) \text {. } \\
\text { 5. Presence of comorbidities increased risk of mortality. }\end{array}$ \\
\hline UK [18] & $\begin{array}{l}20,133 \\
\text { patients. }\end{array}$ & $\begin{array}{l}\text { A. Median age } 73 \text { years (IQR } 58,82) \text {. } \\
\text { B. } 77 \% \text { had documented comorbidity. } \\
\text { C. Common comorbidities were: cardiac disease ( } 31 \%) \text {, uncomplicated } \\
\text { diabetes }(21 \%) \text {, non-asthmatic chronic respiratory disease }(18 \%) \text {, and } \\
\text { CKD }(16 \%) . \\
\text { D. Mortality rate } 26 \% \text {. } \\
\text { E. Increased age and morbidity predicted mortality. }\end{array}$ \\
\hline USA [22] & $\begin{array}{l}5,700 \\
\text { patients }\end{array}$ & $\begin{array}{l}\text { A. Median age, } 63 \text { years (IQR } 52-75) \text {. } \\
\text { B. Common comorbidities were hypertension }(56.6 \%) \text {, obesity }(41.7 \%) \\
\text { and diabetes ( } 33.8 \%) \text {. } \\
\text { C. Median score on the Charlson Comorbidity Index was } 4 \text { points (IQR } \\
\text { 2-6). } \\
\text { C. Outcomes were assessed for } 2,634 \text { patients: } \\
\text { 1. ICU admission, } 373 \text { patients ( } 14.2 \%) \text {. } \\
\text { 2. Mechanical ventilation, } 320(12.2 \%) \text {. } \\
\text { 3. Renal replacement therapy, } 81(3.2 \%) \text {. } \\
\text { 4. Mortality, } 553(21 \%) \text {. }\end{array}$ \\
\hline
\end{tabular}

\subsection{Synergistic Effect}

Ageing and frailty exert a negative effect on the immune system that leads to an increased risk of infection. The ageing immune system is characterized by a low grade and chronic systemic inflammatory state or "InflammAgeing" marked by elevated inflammatory markers such as IL- 6 
and C-reactive protein and is associated with an increased susceptibility to infection [27]. It has been shown that the immune response in patients with COVID-19 is dysregulated and the SARSCoV-2 might mainly act on lymphocytes, (in particular T lymphocytes), induce a cytokine storm in the body, and generate a series of immune responses to damage the corresponding organs [28]. Therefore, immune dysregulation and prolonged inflammation, both of which are prevalent in frailty, may be the key drivers of poor clinical outcomes in patients with Covid-19. Comorbidity and frailty also often overlap and lead to impairment in functional status, quality of life and worse prognosis [29]. It has been shown that $82 \%$ of community dwelling older people who are frail also have comorbidities, $29 \%$ have disability in at least one activity of daily living and $93 \%$ have disability in at least one instrumental activity of daily living [30]. Therefore, ageing, comorbidity and frailty appear to overlap and exert a synergistic effect in older people that increases their vulnerability to infection and risk of adverse outcomes (Figure 1). Also, frailty appears to predict the outcome of COVID-19 better than either age or comorbidity. In a recent multicentre European cohort study, frailty, assessed by clinical frailty score (CFS), proportionately predicted mortality. Compared with CFS 1-2, the adjusted hazard ratios for time from hospital admission to death were 1.55 (95\% Cl 1.00 to 2.41) for CFS 3-4, 1.83 (1.15 to 2.91) for CFS 5-6, and 2.39 (1.50 to 3.81) for CFS 7-9, and adjusted odds ratios for day-7 mortality were 1.22 (95\% Cl 0.63 to 2.38) for CFS 3-4, 1.62 (0.81 to 3.26) for CFS 5-6, and 3.12 (1.56 to 6.24) for CFS 7-9 [31].

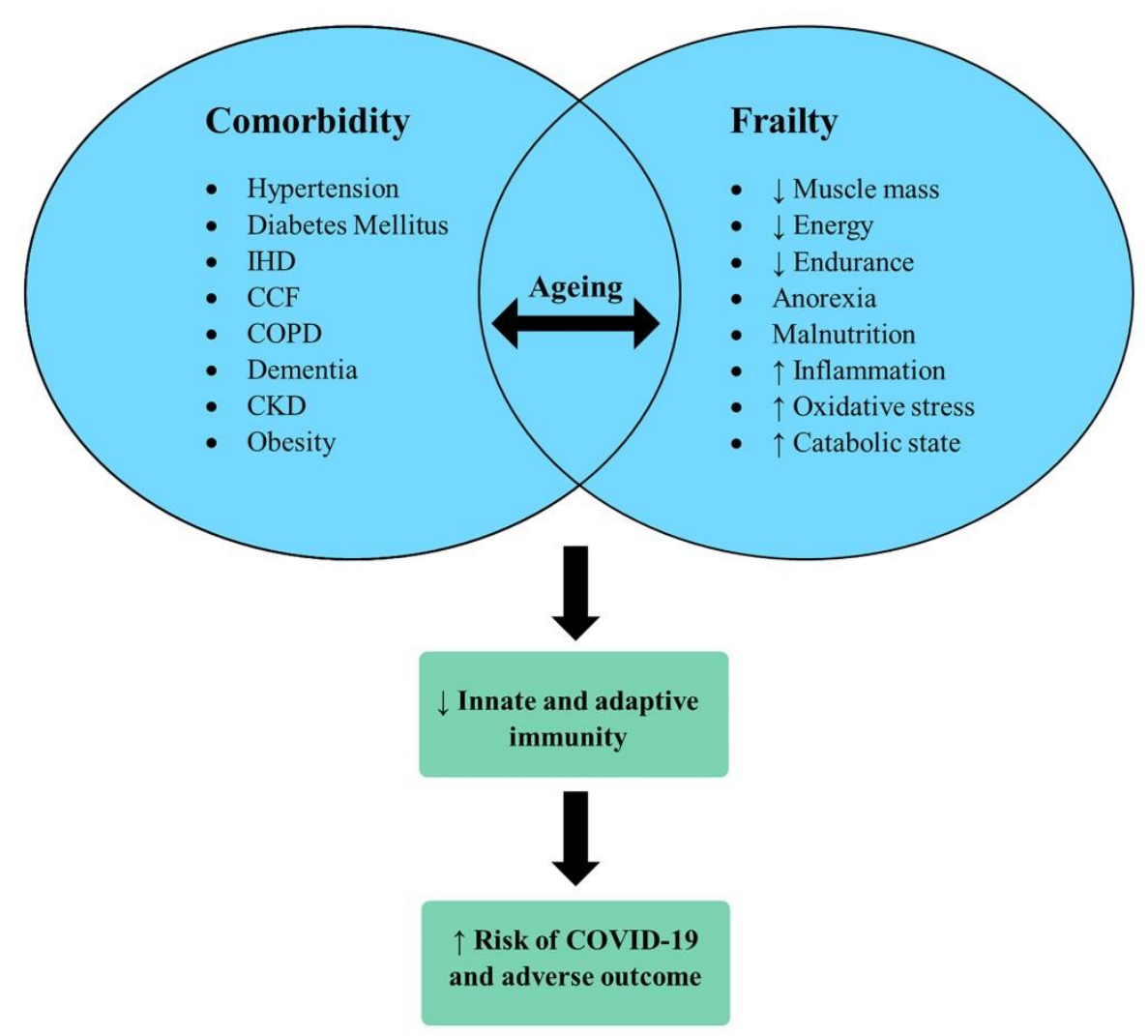

Figure 1 Synergistic effect of aging, comorbidity and frailty reducing immunity and increasing the risk of COVID-19 infection and adverse outcomes. IHD=Ischaemic heart disease, $\mathrm{CCF}=$ Congestive cardiac failure, $\mathrm{COPD}=$ Chronic obstructive pulmonary disease,

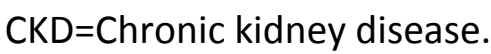




\section{Conclusions}

The global demographics are shifted towards older age. Ageing is associated with increased prevalence of comorbidity and frailty that increase the risk of infections due to dysregulation of the immune system. In addition to the recent COVID-19 pandemic, it has been previously shown that the mortality from influenza was higher in patients who had chronic obstructive pulmonary disease (OR $1.49,95 \% \mathrm{Cl} 1.10$ to 2.01 ), cardiovascular disease $(2.92,1.76$ to 4.86 ) or hypertension $(1.49,1.10$ to 2.10$)$ compared to patients with no comorbidities [32]. Ageing, comorbidity and frailty are also associated with chronic inflammation that is shared with the features of infectious diseases [33]. It has also been shown that lymphocyte number and function are reduced in patients who have died from viral pneumonia compared to those who have survived suggesting that the levels of inflammatory factors in the deceased group were higher than those in the survival group [34].

Both ageing and frailty are indicators of immunosuppression and are significantly associated with worse outcomes. Frail older people in long-term care facilities are vulnerable to respiratory disease outbreaks, including influenza and other human coronaviruses such as the common cold $[35,36]$. Frailty has also been associated with poor post-vaccination immune response and an increased risk of influenza [37]. Frail nursing home residents admitted to hospital were found to be at an increased risk of viral pneumonia (relative risk $\{R R\} 3.06, P=0.01$ ) compared to those admitted from the community [38]. Therefore, older people with COVID-19 are more likely to have underlying comorbidity and frailty which are detrimental to prognosis. These patients may die because of their underlying comorbid conditions. Thorough and systematic assessment of these patients is required from the outset as COVID-19 affects almost all organ systems. These patients require treatment of their pre-existing conditions in addition to the treatment of COVID-19 to reduce the risk of multi-organ failure. Decisions regarding escalation of treatment should include frailty assessment in addition to overall comorbid condition and function. Therefore, frailty score should be part of the initial assessment of patients [39].

\section{Future Perspectives}

So far, there is no specific antiviral agent for COVID-19. Research is currently on-going to develop effective treatment as well as protective vaccination. Due to impaired immunity in older people with comorbidity and frailty, these factors should be considered in risk assessment models in future clinical trials to ensure that the developed vaccines have a good immunogenic response in frail individuals. It appears that COVID-19 mortality is concentrated in older people. Aged population is currently concentrated in the wealthier developed countries, which are able to absorb the financial impact of the pandemic and limit its spread to other countries.

With the global demographic shift towards old age, the sector of older people will exponentially expand, especially in low and middle income countries where heath care resources to face a future pandemic are limited and thus increases the risk of uncontrollable global spread. Therefore, WHO and governments around the world must consider this potential threat in health care planning. Reducing the frailty and comorbidity burden of the future ageing population will be a global necessity. Also, care home populations will increase and future review of policies and 
regulations of these institutions will be required to avoid a future outbreak in these vulnerable settings.

\section{Key Points}

- COVID-19 pandemic is largely concentrated in older people with comorbidity and frailty.

- Age, comorbidity and frailty are synergistic risk factors for COVID-19 adverse outcomes.

- With the demographic shift toward old age, global health care planning is required to improve our resilience for potential future pandemics.

\section{Author Contributions}

Authors contributed equally to the writing of this manuscript.

\section{Competing Interests}

The authors have declared that no competing interests exist.

\section{References}

1. Hui DS, Azhar El, Madani TA, Ntoumi F, Kock R, Dar O, et al. The continuing 2019-nCoV epidemic threat of novel coronaviruses to global health - The latest 2019 novel coronavirus outbreak in Wuhan, China. Int J Infect Dis. 2020; 91: 264-266.

2. Yang J, Zheng Y, Gou X, Pu K, Chen Z, Guo Q, et al. Prevalence of comorbidities in the novel Wuhan coronavirus (COVID-19) infection: A systematic review and meta-analysis. Int J Infect Dis. 2020; 94: 91-95.

3. Ageing and health. World Health Organisation. Accessed May 2020.

4. Wolff JL, Starfield B, Anderson G. Prevalence, expenditures, and complications of multiple chronic conditions in the elderly. Arch Intern Med. 2002; 162: 2269-2276.

5. Karlamangla AS, Singer BH, McEwen BS, Rowe JW, Seeman TE. Allostatic load as a predictor of functional decline: MacArthur studies of successful aging. J Clin Epidemiol. 2002; 55: 696-710.

6. Salive ME. Multimorbidity in older adults. Epidemiol Rev. 2013; 35: 75-83.

7. Kingston $A$, Robinson $L$, Booth $H$, Knapp $M$, Jagger $C$, MODEM project. Projections of multimorbidity in the older population in England to 2035: Estimates from the Population Ageing and Care Simulation (PACSim) model. Age Ageing. 2018; 47: 374-380.

8. Bergman H, Ferrucci L, Guralnik J, Hogan DB, Hummel S, Karunananthan S, et al. Frailty: An emerging research and clinical paradigm-issues and controversies. J Gerontol A Biol Sci Med Sci. 2009; 62: 731-737.

9. Morley JE. Diabetes, sarcopenia, and frailty. Clin Geriatr Med. 2008; 24: 455-469.

10. Shamliyana T, Talley KMC, Ramakrishnan R, Kane RL. Association of frailty with survival: $A$ systematic literature review. Ageing Res Rev. 2013; 12: 719-736.

11. Ofori-Asenso R, Chin KL, Mazidi M, Zomer E, llomaki J, Zullo AR, et al. Global incidence of frailty and prefrailty among community-dwelling older adults a systematic review and metaanalysis. JAMA Netw Open. 2019; 2: e198398. 
12. Wu Z, McGoogan JM. Characteristics of and important lessons from the coronavirus disease 2019 (COVID-19) outbreak in China: Summary of a report of 72314 cases from the Chinese Center for Disease Control and Prevention. JAMA. 2020; 323: 1239-1242.

13. Wu JT, Leung K, Bushman M, Kishore N, Niehus R, de Salazar PM, et al. Estimating clinical severity of COVID-19 from the transmission dynamics in Wuhan, China. Nat Med. 2020; 26: 506-510.

14. Zhou F, Yu T, Du R, Fan G, Liu Y, Liu Z, et al. Clinical course and risk factors for mortality of adult inpatients with COVID-19 in Wuhan, China: A retrospective cohort study. Lancet. 2020; 395: 1054-1062.

15. Chen J, Qi T, Liu L, Ling Y, Qian Z, Li T, et al. Clinical progression of patients with COVID-19 in Shanghai, China. J Infect. 2020; 80: e1-e6.

16. Wu C, Chen X, Cai Y, Zhou X, Xu S, Huang H, et al. Risk Factors associated with acute respiratory distress syndrome and death in patients with coronavirus disease 2019 pneumonia in Wuhan, China. JAMA Intern Med. 2020; 180: 1-11.

17. Onder G, Rezza G, Brusaferro S. Case-fatality rate and characteristics of patients dying in relation to COVID-19 in Italy. JAMA. 2020. doi:10.1001/jama.2020.4683.

18. Docherty AB, Harrison EM, Green CA, Hardwick HE, Pius R, Norman L, et al. Features of 20133 UK patients in hospital with covid-19 using the ISARIC WHO Clinical Characterisation Protocol: Prospective observational cohort study. BMJ 2020; 369: m1985.

19. Williamson E, Walker AJ, Bhaskaran K, Bacon S, Bates C, Morton CE, et al. OpenSAFELY: Factors associated with COVID-19-related hospital death in the linked electronic health records of 17 million adult NHS patients. MedRxiv. doi: https://doi.org/10.1101/2020.05.06.20092999.

20. Li B, Yang J, Zhao F, Zhi L, Wang X, Liu L, et al. Prevalence and impact of cardiovascular metabolic diseases on COVID-19 in China. Clin Res Cardiol. 2020; 109: 531-538.

21. Guan WJ, Liang WH, Zhao Y, Liang HR, Chen ZS, Li YM, et al. Comorbidity and its impact on 1590 patients with Covid-19 in China: A Nationwide Analysis. Eur Respir J. 2020; 55: 2000547.

22. Richardson S, Hirsch JS, Narasimhan M, Crawford JM, McGinn T, Davidson KW, et al. Presenting characteristics, comorbidities, and outcomes among 5700 patients hospitalized with COVID-19 in the New York City Area. JAMA. 2020; 323: 2052-2059.

23. Guo L, Wei D, Zhang $X, W u Y$, Li Q, Zhou $M$, et al. Clinical features predicting mortality risk in patients with viral pneumonia: The MuLBSTA Score. Front Microbiol. 2019; 10: 2752.

24. Yao X, Hamilton RG, Weng NP, Xue QL, Bream JH, Li H, et al. Frailty is associated with impairment of vaccine-induced antibody response and increase in post-vaccination influenza infection in community-dwelling older adults. Vaccine. 2011; 29: 5015-5021.

25. Mortality associated with COVID-19 outbreaks in care homes: Early international evidence. LTC responses to COVID-19. International Long-Term Care Policy Network. Accessed on $14^{\text {th }}$ may 2020.

26. McMichael TM, Currie DW, Clark S, Pogosjans S, Kay M, Schwartz NG, et al. Epidemiology of Covid-19 in a long-term care facility in King County, Washington. NEJM. 2020; 382: 2005-2011.

27. Franceschi C, Bonafe M, Valensin S, Olivieri F, De Luca M, Ottaviani E, et al. Inflamm-aging. An evolutionary perspective on immunosenescence. Ann N Y Acad Sci. 2000; 908: 244-254. 
28. Qin C, Zhou L, Hu Z, Zhang S, Yang S, Tao Y, et al. Dysregulation of immune response in patients with coronavirus 2019 (COVID-19) in Wuhan, China. Clin Infect Dis. 2020; ciaa248. doi: 10.1093/cid/ciaa248.

29. Henchoz Y, Büla C, Guessous I, Santos-Eggimann B. Association between physical frailty and quality of life in a representative sample of community-dwelling swiss older people. J Nutr Health Aging. 2017; 21: 585-592.

30. Wong $\mathrm{CH}$, Weiss D, Sourial N, Karunananthan S, Quail JM, Wolfson C, et al. Frailty and its association with disability and comorbidity in a community-dwelling sample of seniors in Montreal: A cross-sectional study. Aging Clin Exp Res. 2010; 22: 54-62.

31. Hewitt J, Carter B, Vilches-Moraga A, Quinn TJ, Braude P, Verduri A, et al. The effect of frailty on survival in patients with COVID-19 (COPE): A multicentre, European, observational cohort study. Lancet. 2020; S2468-2667(20)30146-8. doi: 10.1016/S2468-2667(20)30146-8.

32. Mertz D, Kim TH, Johnstone J, Lam PP, Kuster SP, Fadel SA, et al. Populations at risk for severe or complicated influenza illness: Systematic review and meta-analysis. BMJ. 2013; 347: f5061.

33. Odegaard JI, Chawla A. Connecting type 1 and type 2 diabetes through innate immunity. Cold Spring Harbor Perspect Med. 2012; 2: a007724.

34. Guo L, Wei D, Zhang X, Wu Y, Li Q, Zhou M, et al. Clinical features predicting mortality risk in patients with viral pneumonia: The MuLBSTA Score. Front Microbiol. 2019; 10: 2752.

35. Lansbury LE, Brown CS, Nguyen-Van-Tam JS. Influenza in long-term care facilities. Influenza Other Respir Viruses. 2017; 11: 356-366.

36. Hand J, Rose EB, Salinas A, Lu X, Sakthivel SK, Schneider E, et al. Severe respiratory illness outbreak associated with human coronavirus NL63 in a long-term care facility. Emerg Infect Dis. 2018; 24: 1964-1966.

37. Yao X, Hamilton RG, Weng NP, Xue QL, Bream JH, Li H, et al. Frailty is associated with impairment of vaccine-induced antibody response and increase in post-vaccination influenza infection in community-dwelling older adults. Vaccine. 2011; 29: 5015-5021.

38. Ma HM, Lee KP, Woo J. Predictors of viral pneumonia: The need for viral testing in all patients hospitalized for nursing home-acquired pneumonia. Geriatr Gerontol Int. 2013; 13: 949-957.

39. COVID-19 Rapid Guideline: Critical Care in Adults; NICE Guideline [NG159]. 2020. Available online: https://www.nice.org.uk/guidance/ng159/chapter/1-Admission-to-hospital (accessed 15th May 2020). 


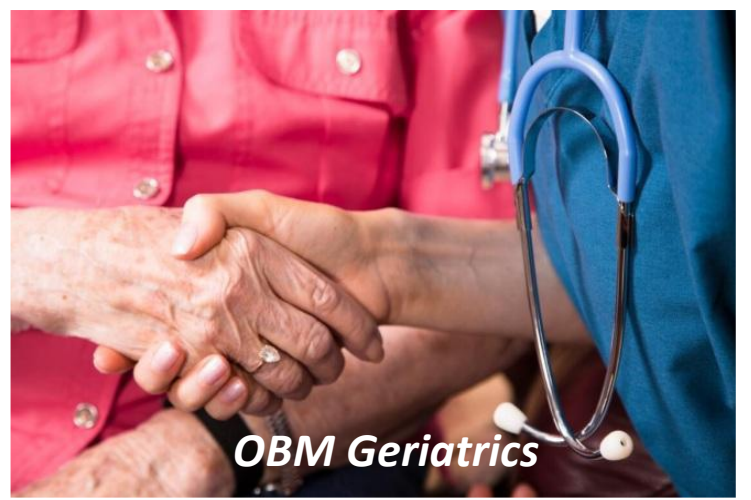

Enjoy OBM Geriatrics by:

1. Submitting a manuscript

2. Joining in volunteer reviewer bank

3. Joining Editorial Board

4. Guest editing a special issue

For more details, please visit:

http://www.lidsen.com/journals/geriatrics 